\title{
ABR AND AUDITORY P300 FINDINGS INCHILDREN WITH ADHD
}

\author{
Eliane Schochat ${ }^{1}$, Claudia Ines Scheuer ${ }^{2}$, Ennio Roberto de Andrade ${ }^{3}$
}

\begin{abstract}
Auditory processing disorders (APD), also referred as central auditory processing disorders (CAPD) and attention deficit hyperactivity disorders (ADHD) have become popular diagnostic entities for school age children. It has been demonstrated a high incidence of comorbid ADHD with communication disorders and auditory processing disorder. The aim of this study was to investigate ABR and P300 auditory evoked potentials in children with ADHD, in a double-blind study. Twenty-one children, ages between 7 and 10 years, with a primary diagnosis of $A D H D$, participated in this experiment. Results showed that all children had normal $A B R$ with normal latency for wave $V$. Results also showed that among 42 ears combined $52.38 \%$ did not have P300. For the medicated subjects we observed that among 28 ears, $42.85 \%$ did not have P300 and for the non-medicated $71.43 \%$ ( $N=14$ ears) did not have $\mathrm{P} 300$. Our results suggest that the medicated subjects had more presence of P300 (57.15\%) than the non-medicated group (28.57\%), though the absence of these potentials were high among the group - 52.38\%.
\end{abstract}

KEY WORDS: ABR, auditory P300, attention deficit hyperactivity disorder (ADHD), attention, methylphenidate.

\begin{abstract}
Achados em ABR e P300 auditivo em crianças com TDAH
RESUMO - Alterações do processamento auditivo, também chamadas alterações no processamento auditivo central e o transtorno do deficit de atenção/ hiperatividade (TDAH), tornaram-se entidades populares nos diagnósticos de crianças escolares. Uma grande incidência de TDAH em comorbidade com alterações na comunicação e com o processamento auditivo central tem sido demonstrada. 0 objetivo deste estudo foi investigar potenciais evocados auditivos, ABR e P300, em crianças com TDAH, em um estudo duplo cego. Vinte e uma crianças, idades entre 7 e 10 anos, com diagnostico primário de TDAH, participaram deste experimento. Os resultados mostraram que todas as crianças tinham ABR com latência normal para a onda $V$ e que, entre 42 orelhas, 52,38\% não tinham P300. Para os sujeitos medicados observou-se que entre 28 orelhas, $42,85 \%$ não tinham P300 e para os não medicados $71,43 \%$ ( $N=14$ orelhas) não tinham P300. Nossos resultados sugerem que os sujeitos medicados tinham maior presença de P300 (57,15\%) do que o grupo não medicado (28,57\%), apesar da ausência desses potenciais serem altos entre o grupo (52,38\%).
\end{abstract}

PALAVRAS-CHAVE: ABR, P300 auditivo, transtorno do déficit de atenção / hiperatividade (TDAH), atenção, metilfenidato.

Auditory selective attention is defined as the ability to facilitate processing of relevant auditory information and inhibit irrelevant information ${ }^{1}$. Lately electrophysiologic assessment of auditory selective attention became possible because of the advent of eventrelated potential (ERP) studies ${ }^{2}$. Auditory processing disorders (APD), also referred as central auditory processing disorders $(C A P D)^{3}$ and attention deficit hyperactivity disorders (ADHD) have become popular diagnostic entities for school age children. Despite the common use of both terms, differentiation of this diagnosis for professionals remains a challenge. Indeed, there are many behaviors that children (and adults) with APD and ADHD have in common.

Recorded prevalence rates for ADHD vary substantially, partly because of changing diagnostic criteria over time, and partly because of variations in ascertainment in different settings and the frequent use of referred samples to estimate rates. A recent review of prevalence rates in school-aged community samples (rather than referred samples) indicates rates varying from $4 \%$ to $12 \%$, with estimated prevalence based on combining these studies of $8 \%$ to $10 \%$. In the general population, $9.2 \%(5.8 \%-13.6 \%)$ of males and $2.9 \%$

Departamento de Fisioterapia, Fonoaudiologia e Terapia Ocupacional (Curso de Fonoaudiologia) da Faculdade de Medicina da Universidade de São Paulo (FMUSP), São Paulo SP, Brasil: ${ }^{1}$ Professora Associada; ${ }^{2}$ Professora Doutora; ${ }^{3}$ Médico Psiquiatra, responsável pelo Ambulatório dos Transtornos do Déficit de Atenção / Hiperatividade do Serviço de Psiquiatria da Infância e Adolecência (SEPIA) do Instituto de Psiquiatria do Hospital das Clínicas da FMUSP.

Received 28 November 2001, received in final form 24 April 2002. Accepted 2 May 2002. 
(1.9\% - 4.5\%) of females are found to have behaviors consistent with ADHD. With the DSM IV criteria ${ }^{4}$ (compared with earlier versions), more females have been diagnosed with the predominantly inattentive type. Revisions of DSM-IV ${ }^{4}$ reestablished the use of multiple domains of symptoms and subtypes of the disorder. Therefore this disorder can be mainly inattentive as it occurs in girls, or impulsive/ hyperactive, observed in boys. Generally two symptoms can co-occur; it is the case of hyperactivity and impulsivity. The symptoms of inattention are located in a separate domain ${ }^{5}$.

It has been demonstrated a high incidence of comorbid ADHD with communication disorders and auditory processing disorder (APD) ${ }^{6}$. Moreover, it has been shown that many individuals with ADHD perform poorly on tests of central auditory function. This has led some investigators to conclusions that are controversial and difficult to understand. An auditory processing disorder (APD) may be broadly defined as a deficit in the processing of information that is specific to the auditory modality. It may be associated with difficulties in listening, speech understanding, language development, and learning. In its pure form, however, it is conceptualized as a deficit in the processing of auditory input ${ }^{3}$. APD results from dysfunction of processes dedicated to audition; however, APD may also coexist with more global dysfunction that affects performance across modalities (e.g., attention deficit, neural timing deficits, and language representation deficit). APD has been observed in diverse clinical populations. Those where a central nervous system pathology or a neurodevelopmental disorder is suspected (e.g., developmental language disorder, dyslexia, learning disabilities, attention deficit disorder) and those where evidence of central nervous system pathology is clear (e.g., aphasia, multiple sclerosis, epilepsy, traumatic brain injury, tumor, and Alzheimer's disease).

Cognitive processes of attention refer that distinct neural networks accomplish component processes of alerting, orienting and executive control. Neuroanatomical bases and the neural circuitry for alerting are centered in the right frontal lobe, including the right parietal lobe and locus ceruleus. Orienting is connected to the posterior parietal lobes, including the superior colliculus and thalamus, and the executive control connects to the anterior cingulate gyrus, including the left lateral frontal lobe and basal ganglia?.

Other technical terms are used to describe attention:- the alerting process and right frontal network operate to establish sustained attention, the orienting process and posterior parietal network ope- rate to establish selective attention and the divided attention is related to executive control and the anterior cyngulate network. ADHD may be linked to these processes ${ }^{7}$. Although attention deficits frequently characterize APD and ADHD (particularly the combined and predominantly inattentive types), there are distinctions to be drawn regarding the nature of the inattention observed in the two disorders. The attention deficits of ADHD typically are pervasive and supra modal, impacting more than one sensory modality 4 . In contrast, individuals with APD experience attention deficits that may be restricted to the auditory modality ${ }^{8}$. Left-ear deficit on dichotic speech tests and a depressed auditory performance under conditions of either contralateral or ipsilateral competition have been seen as a function of the level of brain dysfunction, which argues against pervasive attention deficit in APD and helps distinguish APD from $A D H D^{9,10}$. Other authors studied the relationship between APD and ADHD in a double blind, placebo-controlled, single-cross-over study of methylphenidate, in boys who met the criteria for ADHD and control boys ${ }^{10,11}$. Their conclusion sustained that attention is a critical feature of performance on APD tests, albeit the current diagnostic criteria for APD make a clinical separation of the two disorders problematic. Another conclusion was that stimulants appear to be a useful treatment for the symptoms of both ADHD and APD and that APD tests might be a useful measure of ADHD symptomatology and a response to stimulants.

A double-blind placebo study investigated the effects of methylphenidate on three tests of auditory processing in children diagnosed with both ADHD and $A P D^{12}$. Results pointed that methylphenidate did not have a significant effect on any of the central auditory processing measures although it was found that their performance improved significantly on the attention/impulsivity test. It should be noted that improvement in the child's attentive ability facilitates the AP evaluation, with less stress on the child and tester.

Into what respects to stimulants ${ }^{13}$, methylphenidate (MP) is a drug that blocks the dopamine (DA) and the norepinephrine transporter, and it is hypothesized that these pharmacological actions are relevant to its therapeutic effects. Particularly relevant are its effects on DA transporters (DAT) in view of the recent findings documenting significant increases in DAT in subjects with ADHD ${ }^{14,15}$ and the reported association between expression of the DAT1 allele and scores of hyperactivity-impulsivity in subjects with ADHD ${ }^{16}$. Therapeutic doses ${ }^{17}$ of oral MP $(0.25$ - 
$1 \mathrm{mg} / \mathrm{kg}$ ) induced significant DAT blockade (50-75\%) in the human brain ${ }^{18}$. Because DAT is the main mechanism for removal of extracellular DA in brain ${ }^{19}$, one could predict that oral MP should increase extracellular DA. In fact, it has been hypothesized that MP acts by increasing resting levels of extracellular DA, which stimulate DA autoreceptors attenuating DA release in response to activation ${ }^{20}$.

Functional diagnostic techniques in neurosciences as evoked potential recording (ERP) have become very useful. Latency prolongations are objective evidence of clinical or subclinical disease and long latency potentials like the P300 are useful in studying cognitive and attentional functions. The use of auditory evoked potentials (AEP) can help in differentiating some of the overlapping behaviors. Relations between ERP and ADHD established ${ }^{21}$ the performance in an auditory and visual modality on event relate potential (ERP) in ADHD children and normal controls (7-13 yr. old). In the auditory task, controls had more correct detection (hits), less false alarms, larger P3b amplitudes to nontarget stimuli, as well as larger early frontal positivity (100-250 ms) to target stimuli than ADHD subjects. It was hypothesized that for ADHD children, in both the auditory and the visual task, there is a deficit in the activation of the P3b process. Incorrect triggering of the $\mathrm{P} 3 \mathrm{~b}$ process might be caused by disturbances in other aspects of the attention process, preceding the $\mathrm{P} 3 \mathrm{~b}$. Under certain recording and stimulus conditions the P300 wave may be bimodal (i.e., P3a and P3b). The "a" component appears to have a frontal distribution whereas the " $b$ " seems to have a parietal distribution ${ }^{22}$.

Recently ${ }^{23}$ recorded event-related potentials of 9 year-old children with and without ADHD. Their results suggest that increased distractibility may be associated with an abnormally strong cerebral orienting towards non-attended stimuli. A later negativity at around $300 \mathrm{~ms}$ was significantly smaller in the children with ADHD than for the control group. For the authors, these findings demonstrate that eventrelated potential measures may be useful in helping to understand the information processing found in distractible children.

The overall purpose of this research was to investigate $A B R$ and $P 300$ auditory evoked potentials in children with $A D H D$, in a double-blind study, in order to analyze their performance in AEP.

\section{METHOD}

Subjects - Twenty-one children, ages between 7 and 10 years, with a primary diagnosis of ADHD, participated in this experiment. All subjects had histories of normal hearing, as well as normal or adapted vision. A double blind study was performed, the audiologists did not know whether or not the subjects were taking methylphenidate.

All ADHD subjects were recruited from the Ambulatory of Attention Deficit and Hyperactivity Disorders, Hospital das Clínicas, School of Medicine, University of São Paulo, through a psychiatrist specialized in the assessment of ADHD children, as well as other learning and behavioral disorders of childhood. All ADHD subjects met the full criteria for ADHD according to DSM-IV ${ }^{4}$ criteria. This research was approved by the Sub-Commission of Ethics and Research, Department of Physiotherapy, Communication/ Language Disorders and Occupational Therapy, School of Medicine, University of São Paulo. Parents or responsible for the child fulfilled the post information forms.

Acquisition of event related potentials - Auditory ERPs were elicited using an "oddball" paradigm. Tone stimuli (100 ms duration, $10 \mathrm{~ms}$ rise and fall time) at $70 \mathrm{~dB} \mathrm{nHL}$ were presented monaurally through headphones at a rate of 1.1/s. Eighty five percent of the tones were $1000 \mathrm{~Hz}$ (background tones) and the remaining fifteen percent were $750 \mathrm{~Hz}$ (target tones). The sequence of tones was randomly intermixed with the constraint that no two-target tones were presented in succession. The stimulus-evoked responses were recorded from the midline site $(\mathrm{Cz})$ of the international 10-20 system. Linked earlobes served as reference. Ground electrode was placed at the forehead. All electrode impedance was maintained at $5 \mathrm{KW}$ or less throughout the recording.

All subjects were seated in a reclining comfortable chair. Auditory thresholds were determined before. This was followed by the demonstration of the two tones to be presented. Subjects were instructed to mentally counting the deviant stimuli they heard (i.e. those that deviate from a sequence of standard stimuli).

\section{RESULTS}

All children had normal ABR with normal latency for wave V. Some delayed P300 was found, some small, and others absent. Out of 21 subjects tested, $14(66.6 \%)$ used medication and 7 (33.3\%) did not (Table 1).

Among 42 ears combined ( 21 left, 21 right) 52.38\% did not have P300. For the right and for the left ear $(n=21) 47.85 \%$ (9) did not have any P300. Medicated subjects (Table 2 ) results showed that subjects' 28 ears (14left, 14 right) $42,85 \%$ did not have P300. For the right ear $(n=14) 35.71 \%$ and $42.85 \%$ for the left ear $(n=14)$ did not have any P300.

Table 3 points to 14 ears (7 left, 7 right) of the nonmedicated subjects, that $71.43 \%$ did not have P300. For the right ear $(n=7) 57.14 \%$ and $42.85 \%$ for the left ear $(n=7)$ did not have any P300.

Fisher test was applied to data contained in Table 3 (Table 4) in order to see if there was a statistical 
Table 1. Medicated and non- medicated ADHD children.

\begin{tabular}{|c|c|c|c|c|c|c|}
\hline \multirow[b]{2}{*}{$S$} & \multirow[b]{2}{*}{ Medication } & \multicolumn{2}{|c|}{ Right ear } & \multicolumn{2}{|c|}{ Left ear } & \multirow[b]{2}{*}{ CONC } \\
\hline & & LAT* & $\mathrm{AMP}^{* *}$ & LAT* & $\mathrm{AMP}^{* *}$ & \\
\hline 1. & + & None & - & none & - & Alt. \\
\hline 2. & + & 276.00 & 8.91 & 291.00 & 17.46 & $\mathrm{NI}$ \\
\hline 3. & + & 298.50 & 8.53 & 282.00 & 5.34 & $\mathrm{NI}$ \\
\hline 4. & + & 334.50 & 8.43 & 310.50 & 5.97 & $\mathrm{NI}$ \\
\hline 5. & - & 322.50 & 8.76 & 297.00 & 6.83 & $\mathrm{NI}$ \\
\hline 6. & - & none & - & none & - & Alt. \\
\hline 7. & + & 332.50 & 7.35 & 291.00 & 9.20 & $\mathrm{NI}$ \\
\hline 8. & + & 283.50 & 4.68 & 295.50 & 7.31 & $\mathrm{NI}$ \\
\hline 9. & - & 324.00 & 4.81 & none & - & Alt. \\
\hline 10. & - & none & - - & none & - & Alt. \\
\hline 11. & - & 330.00 & 5.34 & 250.50 & 6.96 & $\mathrm{NI}$ \\
\hline 12. & + & 349.50 & 5.82 & none & - & Alt. \\
\hline 13. & + & none & - & none & - & Alt. \\
\hline 14. & + & 324.00 & 21.76 & 312.00 & 20.41 & NI. \\
\hline 15. & - & none & - - & 352.50 & 7.25 & Alt \\
\hline 16. & + & none & - & none & - & Alt. \\
\hline 17. & + & 286.50 & 7.19 & 300.00 & 4.00 & $\mathrm{NI}$ \\
\hline 18. & + & 297.00 & 6.17 & 388.50 & 6.13 & $\mathrm{NI}$ \\
\hline 19. & + & none & & none & - & Alt. \\
\hline 20. & - & none & - & 291.00 & 8.94 & Alt. \\
\hline 21. & + & none & — & none & - & Alt. \\
\hline
\end{tabular}

*LAT (latency) measured in milliseconds. **AMP (amplitude) measured in microvolts. + medicated; -, non medicated; Alt, altered; $\mathrm{NI}$, normal; c, conclusion.

significant difference between the medicated and the non-medicated subjects.

\section{DISCUSSION}

Although with a small group of children and no statistical significant difference, our results suggest that the medicated subjects had more presence of P300 (57.15\%) than the non-medicated group (28.57\%), though the absence of these potentials were high among the group, $52.38 \%$.

Long latency potentials ${ }^{23}$ like the P300 are useful in studying cognitive and attentional functions, observing that if the P300 is abnormally small or delayed, there is probably some alteration in cognitive processing. Latency is a much more reliable indicator than amplitude, since latency is difficult to alter with at- tention. Also, P300 amplitude may be reduced in some forms of ADHD, and may improve with treatment, corroborating our findings. Maybe, reasons for these absences are the structures involved in generation of the auditory $\mathrm{P} 300$ and the pathophysiology of ADHD. Generators of the P300 are the reticular formation, pre-frontal cortex, centro parietal cortex, temporal cortex, limbic system (hypocampo), and some thalamus contribution; casually structures involved in attention ${ }^{24}$. Moreover, selective attention, which is one of the necessary components for theP300, probably goes through the following circuit: ponsthalamus - sub cortex (basal ganglia) - auditory cortex -association cortex - frontal cortex - limbic system - cingular gyrus - basal forebrain (amygdala) reticular formation. Probably, this led to the low presence of the P300 found in our study for all subjects. 
Table 2. Medicated subjects.

\begin{tabular}{|c|c|c|c|c|c|}
\hline \multirow[b]{2}{*}{$S$} & \multicolumn{2}{|c|}{ Right ear } & \multicolumn{2}{|c|}{ Left ear } & \multirow[b]{2}{*}{ CONC } \\
\hline & $\mathrm{LAT}^{*}$ & $\mathrm{AMP}^{* *}$ & LAT* & AMP** & \\
\hline 1. & None & - & none & - & Alt. \\
\hline 2. & 276.00 & 8.91 & 291.00 & 17.46 & $\mathrm{NI}$ \\
\hline 3. & 298.50 & 8.53 & 282.00 & 5.34 & $\mathrm{NI}$ \\
\hline 4. & 334.50 & 8.43 & 310.50 & 5.97 & $\mathrm{NI}$ \\
\hline 5. & 332.50 & 7.35 & 291.00 & 9.20 & $\mathrm{NI}$ \\
\hline 6. & 283.50 & 4.68 & 295.50 & 7.31 & $\mathrm{NI}$ \\
\hline 7. & 349.50 & 5.82 & none & - & Alt. \\
\hline 8. & None & - & none & - & Alt. \\
\hline 9. & 324.00 & 21.76 & 312.00 & 20.41 & NI. \\
\hline 10. & None & - & none & - & Alt. \\
\hline 11. & 286.50 & 7.19 & 300.00 & 4.00 & $\mathrm{NI}$ \\
\hline 12. & 297.00 & 6.17 & 388.50 & 6.13 & $\mathrm{NI}$ \\
\hline 13. & None & - & none & - & Alt. \\
\hline 14. & None & - & none & - & Alt. \\
\hline
\end{tabular}

*LAT (latency) measured in milliseconds. **AMP (amplitude) measured in microvolts. Alt, altered; NI, normal; c, conclusion.

Table 3. Non-medicated subjects.

\begin{tabular}{|c|c|c|c|c|c|}
\hline \multirow[b]{2}{*}{$S$} & \multicolumn{2}{|c|}{ Right ear } & \multicolumn{2}{|c|}{ Left ear } & \multirow[b]{2}{*}{ CONC } \\
\hline & $\mathrm{LAT}^{*}$ & $\mathrm{AMP}^{* *}$ & $\mathrm{LAT}^{*}$ & $\mathrm{AMP}^{* *}$ & \\
\hline 1. & 322.50 & 8.76 & 297.00 & 6.83 & $\mathrm{NI}$ \\
\hline 2. & None & - & none & - & Alt. \\
\hline 3. & 324.00 & 4.81 & none & - & Alt. \\
\hline 4. & none & - & none & - & Alt. \\
\hline 5. & 330.00 & 5.34 & 250.50 & 6.96 & $\mathrm{NI}$ \\
\hline 6. & none & - & 352.50 & 7.25 & Alt \\
\hline 7. & none & - & 291.00 & 8.94 & Alt. \\
\hline
\end{tabular}

*LAT (latency) measured in milliseconds. **AMP (amplitude) measured in microvolts. Alt, altered; NI, normal; c, conclusion.

Table 4. Fisher test*.

\begin{tabular}{lccccc}
\hline & \multicolumn{5}{c}{ Groups } \\
\cline { 2 - 3 } & \multicolumn{2}{c}{ Medicated } & & \multicolumn{2}{c}{ Non medicated } \\
\cline { 2 - 3 } \cline { 5 - 6 } & $\mathrm{N}$ & $\%$ & & $\mathrm{~N}$ & $\%$ \\
\hline Abnormal & 6 & 42.9 & & 5 & 71.4 \\
Normal & 8 & 57.1 & & 2 & 28.6 \\
Total & 14 & 100 & & 7 & 100 \\
\hline
\end{tabular}

${ }^{*} p=0.3615$ (not significant)
In addition to, we divided the group in order to verify if there were differences between the medicated and non-medicated groups, and we observed differences in the performance of both.

It was pointed out ${ }^{17}$ that significant increases in extracellular dopamine (DA) after oral MP in humans caused by the blockade of the dopamine transporters (DAT) by MP predominantly reflects an amplification of spontaneously released DA. Subjects with ADHD, in whom increased brain levels of DAT are likely to result in rapid removal of DA from the extracellular space, may exhibit deficits of DA that are corrected by treatment with MP. Therefore, auditory P300 is an ERP, which requires selective attention from the subjects.

Reduction in MMN (mismatch negativity) amplitude in children with ADHD demonstrated that methylphenidate enhanced MMN amplitude, along with increased performance level (hit rate) in children with ADHD. Our results are in accordance to these results; with the theory that ADHD is a noradrenergic/ dopaminergic disorder ${ }^{25}$ and with the evidence of noradrenergic/ dopaminergic manipulation of auditory selective attention ${ }^{26}$. When interpreting these findings of abnormalities in auditory selective attention in ADHD, it should be kept in mind that comorbidity of ADHD with conduct disorder or tic disorder is quite common.

The basal ganglia and the amygdala are very important anatomic structures. Anatomic neuroimaging studies suggest that the relevant regulatory circuits of the ADHD include the prefrontal cortex and the basal ganglia, which are modulated by dopaminergic inervation from the midbrain ${ }^{27}$. Some researchers demonstrated the role for the basal forebrain cholinergic system in the regulation of attentional processes engaged in sustained or selective attention tasks ${ }^{28-30}$.

Though, clearly much more work must be done in differentiating APD from ADHD, there are some ways in which insights can be gained that may assist in the differentiation of these two disorders. By comparing behavioral profiles, as well as administering behavioral and electrophysiologic central auditory tests, the clinician may garner enough information to begin to untangle the APD - ADHD mystery.

Assessment of the neurobiologic mechanisms that underlie auditory selective attention is quite challenging, partly because it is difficult to design an animal experiment using similar paradigms to those applied in humans. Finally, considerable studies need to focus on the concept of APD and ADHD disorders and more studies must be done on sensitivity and specificity of the instruments currently in use for the diagnosis of APD and ADHD. 


\section{REFERENCES}

1. Näätänen R. Auditory ERPs and attention: multi-channel tasks (selective attention). In Attention and brain function. Hillsdale, NJ: Lawrence Erlbaum Associates, 1992: 247-305.

2. Hillyard SA, Hink RF, Schwent VL, Picton TW. Electrical signs of selective attention in the human brain. Science 1973;182:177-180.

3. Jerger J, Musiek F. Report of the Consensus Conference on the Diagnosis of Auditory Processing Disorders in School-Aged Children. J Am Acad Audiol 2000;11:467-474.

4. American Psychiatric Association. Diagnostic and statistical manual for mental disorders review. 4.Ed. Washington, DC, American Psychiatric Association, 1995.

5. Swanson J, Posner MI, Cantwell D, et al. Attention-deficit/hyperactivity disorder: symptom domains, cognitive processes and neural networks. In Parasuranam R, The attentive brain. Cambridge: MIT Press, 1998:445-461.

6. Baker L, Cantwell DP. The association between emotional/behavior disorders and learning disorders in children with speech/language disorders. Adv Learn Behav Disab 1990;6:27-46.

7. Posner M, Raichle ME. Images of mind. Scientific American Library,1994.

8. Chermak GD, Hall III JW, Musiek FE. Differential diagnosis and management of central auditory processing disorder and attention deficit hyperactivity disorder. J Am Acad Audiol 1999;10:289-303.

9. Musiek FE, Kibbe K, Baran JA. Neuroaudiological results from splitbrain patients. Seminars in Hearing 1984;5:219-230.

10. Jerger S, Johnson K, Loiselle L. Pediatric central auditory dysfunction: comparison of children with a confirmed lesion versus suspected processing disorders. Am J Otol1988;9:63-71.

11. Cook JR, Mausbach T, Burd L, et al. A preliminary study of the relationship between central auditory processing and attention deficit disorder. J Psych Neurol 1993;18:130-137.

12. Tillery KL, Katz J, Keller WD. Effects of methylphenidate (Ritalin) on auditory performance in children with attention and auditory processing disorders. J Speech Lang Hear Res 2000;43:893-901.

13. Solanto MV. Neuropsychopharmacological mechanisms of stimulant drug action in attention-deficit hyperactivity disorder: a review and integration. Behav Brain Res 1998;94:127-52.

14. Dougherty DD, Bonab AA, Spencer TJ, Rauch SL, Madras BK, Fischman AJ. Dopamine transporter density in patients with attention deficit hyperactivity disorder. Lancet 1999;354:2132-2133.

15. Krause KH, Dresel SH, Krause J, Kung HF, Tatsch K. Increased striatal dopamine transporter in adult patients with attention deficit hyperactivity disorder: effects of methylphenidate as measured by single photon emission computed tomography. Neurosci Letters 2000;285:107-110
16. Waldman ID, Rowe DC, Abramowitz A, et al. Association and linkage of the dopamine transporter gene and attention-deficit hyperactivity disorder in children: heterogeneity owing to diagnostic subtype and severity. Am J Hum Genet 1998;63:1767-776.

17. Volkow ND, Chang L, Wang GJ, et al. Higher cortical and lower subcortical metabolism in detoxified methamphetamine abusers. Am J Psychiatry 2001;158:383-389.

18. Volkow ND, Wang GJ, Fowler JS, et al. Dopamine transporter occupancies in the human brain induced by therapeutic doses of oral methylphenidate. Am J Psychiatry 1998;155:1325-1331.

19. Giros B, Jaher M, Jones SR, Wightman RM, Caron MG. Hyperlocomotion and indifference to cocaine and amphetamine in mice lacking the dopamine transporter. Nature 1996;379: 606-612.

20. Seeman P,Madras BK. Anti-hyperactivity medication: methylphenidate and amphetamine. Molec Psychiatry 1998;3:386-396.

21. Jonkman LM, Kemner C, Verbaten MN, et al. Event-related potentials and performance of attention-deficit hyperactivity disorder: children and normal controls in auditory and visual selective attention tasks. Neuroreport 1999;10:1869-1874.

22. Kilpelainen R, Luoma L, Herrgard E, Ypparila H, Partanen J, Karhu J Persistent frontal P300 brain potential suggests abnormal processing of auditory information in distractible children. Neuroreport 1999;10:3405-3410.

23. Picton TW. The P300 wave of the human event related potential. J Clin Neurophysiol 1992;9:456-479.

24. Kraus N, Mc Gee T. Auditory event related potentials. In Katz J (ed). Handbook of clinical audiology. Baltimore: Williams \& Wilkins,1994: 406-423.

25. Biederman J, Spencer T. Attention-deficit/hyperactivity disorder (ADHD) as a noradrenergic disorder. Biol Psychiatry 1999;46:1234-1242.

26. McKetin R, Ward PB, Catts SV. Changes in auditory selective attention and event-related potentials following oral administration of Damphetamine in humas. Neuropsychopharmacology 1999;21:380-390.

27. Castellanos FX. Toward a pathophysiology of attention-deficit/ hyperactivity disorder. Clin Pediatr 1997;36:381-393.

28. Muir WJ, St Clair DM, Blackwood DH, Roxburgh HM, Marshall I. Eyetracking dysfunction in the affective psychoses and schizophrenia. Psychol Med 1992;22:573-580.

29. Pang L, Lazar DF,Moller DE, Flier JS, Saltiel AR. The stimulation of pp42 mapkinase by insulin does not correlate with its metabolic actions in cells overexpressing mutant insulin receptors. Biochem Biophys Res Commun 1993;196:301-310.

30. Voytko ML, Olton DS, Richardson RT, Gorman LK, Tobin JR, Price DL. Basal forebrain lesions in monkeys disrupt attention but not learning and memory. J Neurosci 1994;14:167-186. 